\title{
XXVI. A method of measuring the self-inductance of small loops
}

\section{F.B. Pidduck M.A.}

To cite this article: F.B. Pidduck M.A. (1921) XXVI. A method of measuring the selfinductance of small loops, Philosophical Magazine Series 6, 42:248, 220-227, DOI: 10.1080/14786442108633756

To link to this article: http://dx.doi.org/10.1080/14786442108633756

曲 Published online: 08 Apr 2009.

Submit your article to this journal $\pi$

Џ Article views: 2

Q View related articles $\square$

Citing articles: 1 View citing articles ๘ 
(di) The effect of varying the reaction coupling on the form of the anode and grid current variations is studied and the results explained in terms of the simple theory (a) and the filament cooling effect $(c)$. Secondary emission is found to play an important part in the action of a triode even at low anode potentials.

(e) A method of investigating the Joulean heating effect of the filament by the emission current is described, and it is shown that when the emission current flows through the filament in the same direction as the filament curreut the emission is 25 per cent. greater than when it flows in opposition.

$\left(f^{\prime}\right)$ A further discussion of the thermal altemtions produced in the filament on closing the anote circuit shows the possibility of running the electronic discharge without a filament heating battery, the filament being maintained at an emitting temperature by the effect of the emission current itself. A special method of starting such a discharge would be required.

XXVI. A Method of Measuring the Self-inductance of Small Loops. By F. B. PidDuck, M.A., University Lectwerer. in Applied Mathematic's and Fellow of Queen's Cullege, Oxford *.

\section{Introduction.}

THE suggestion has several times been made of an alternating current galvanometer based on the couple experienced by a ring or disk suspended in an alternating magnetic field $\dagger$. It appeared to the writer that the method could be advantageously used to determine small self-inductances in absolute measure, as considerable forces can be developed in quite small rings $¥$. If a plane circuit of area $A$ lies in a uniform magnetic tield of strength $H$ cos pt at time $t$, its normal making an angle $\theta$ with the field, it is easy to show $\S$ that the mean couple on the eircuit is

$$
\frac{\mathrm{L} p^{2} \mathrm{H}^{2} \mathrm{~A}^{2}}{2\left(\mathrm{~L}^{2} p^{2}+\mathrm{R}^{2}\right)} \cos \theta \sin \theta
$$

* Communicated by the Author.

$\dagger$ J. A. Fleming, Electrician, xviii. p. 561 (1887); Elihu Thomson, Trans. Amer. Inst. Electr. Eng. iv. p. 160 (1887).

$\mp$ On the measurement of small inductance, see L. Pierauer, Wied. Ann. liii. p. 772 (1894); M. Wien, Wred. Ann. liji. p. 928 (1894); F. Dolezalek, Zeitschr. f. Instrumentenliunde, xxiii. p. 246 (1903); A. H. Taylor, Phys. Rev, xix. p. 273 (1904); E. Giebe, Ann. d. Phys. [4] xxiv. p. $941(1907)$.

\$ Cf. G. T. Walker, Phil. Trans, A. 183, p. 290 (1891). 
tending to increase $\theta$. If the circuit is not plane we can nevertheless associate with it a plane circuit, rigidly attached to it, such that the areas of projection on any plane are equal. If the circuit is suspended by a torsion fibre giving a couple of $\mu$ units per radian, and $\alpha$ is the deflexion produced by an alternating field of effective strength $\mathrm{H}$,

$$
\mu \alpha=\frac{\mathrm{L}_{2}^{2} \mathrm{H}^{2} \mathrm{~A}^{2}}{\mathrm{~L}^{2} p^{2}+\mathrm{R}^{2}} \cos \theta \sin \theta .
$$

Writing I for the moment of inertia of the circuit abont the suspending fibre, and $\mathrm{T}$ for the time of swing in the absence of a magnetic field, we have therefore

$$
\frac{\mathrm{L} p^{2}}{\mathrm{~L}^{2} p^{2}+\mathrm{R}^{2}}=\frac{8 \pi^{2} \mathrm{I} \alpha}{\mathrm{H}^{2} \mathrm{~A}^{2} \mathrm{~T}^{2} \sin 2 \theta} .
$$

It is advantageous to work near the position $\theta=\frac{1}{4} \pi$, when $\sin 2 \theta$ may be put equal to unity. Then we have for low frequencies, where $\mathrm{L} p / \mathrm{R}$ is small,

$$
\mathrm{L}=2 \mathrm{I} \alpha\left[\frac{\mathrm{R}}{q \mathrm{HAT}}\right]^{2}, \ldots . . .
$$

$q$ being the frequency of the alternating current. For high frequencies, where $\mathrm{Lp} / \mathrm{R}$ is large,

$$
\mathrm{L}=\frac{\mathrm{H}^{2} \mathrm{~A}^{2} \mathrm{~T}^{2}}{8 \pi^{2} \mathrm{I} \alpha} . \quad . \quad . \quad . \quad . \quad .
$$

To measure $\mathrm{R}$ in situ we may substitute for the alternating field a constant field $H$, and measure the damping about the position $\theta=\frac{1}{4} \pi$. The damping factor in a small swing is $e^{-\lambda t}$, where

$$
\lambda=\mathrm{const}+\frac{\mathrm{H}^{2} \mathrm{~A}^{2}}{4 \mathrm{RI}} \cdot . \quad . \quad . \quad .
$$

The making and breaking of the exciting current will itself provide a momentary couple for setting the coil in motion.

\section{Lou-frequency experiments.}

Experiments with alternating current of low frequency showed that the effacts observed are approximately of the right magnitude, but several causes combine to render sucb experiments inaccurate. The value of $R$ derived from the damping experiments, not in themselves very accurate, is squared in (1), and the same holds of the magnitude and frequency of the exciling current. The irreguiarities of 
these are such that the oscillations of the ring can rarely be reduced below $5 \mathrm{~mm}$. on the scale. To minimize them it was decided to keep the current constantly adjusted with a Kelvin's ampere balance as indicator, and to use a stroboscopic indicatur for the speed. The axle of the alternator carried a brass disk $10 \mathrm{~cm}$. in diameter, pierced with two slits $3 \mathrm{~cm}$. long by $2 \mathrm{~mm}$. wide, equidistant from the centre on opposite sides. On one side of the disk was a small glowlamp, on the other an electrically maintained tuning-fork of frequency 50. The intermittent illumination makes the fork appear bent into a sinuous form (with a curious appearance of melting), the waves moving backwards or forwards along the prongs with a frequency $2 q-50$. The sinuosities are kept steady with a field rheostat on the D.C. side, and thus $q$ is kept at 25 , within less than 1 per cent.

The aliernating magnetic field was produced with a pair of coils arranged in Helmholtz's fashion for a uniform field. Gach coil had 500 turns, and the average of their mean radii nas $17.82 \mathrm{~cm}$. When placed with their centres at $17.72 \mathrm{~cm}$. apart they gave a field of 25.4 gausses per ampere. The suspended circuits were three in number :-

(1) A copper ring of mean radius $2.030 \mathrm{~cm}$. and diameter of wire $0199 \mathrm{~cm}$, mass $3.666^{\circ} \mathrm{gm}$. The calculated moment of inertia about a diameter was $7 \cdot 560$ C.G.S. units, its mean area $12.95 \mathrm{~cm} .^{2}$

(2) An aluminium ring of mean radius $1.735 \mathrm{~cm}$. and rectangular section, axial width $0.33 \mathrm{~cm}$. and radial width $0.35 \mathrm{~cm}$., mass $3.085 \mathrm{gm}$. The calculated moment of inertia was $4 \cdot 685$, its mean area $9 \cdot 460 \mathrm{~cm}^{2}$

(3) A solenoid of 54 turns of enamelled S.W.G. 20 wire, closely wound on a wooden core. Mean diameter $10.05 \mathrm{~cm}$., length $5.45 \mathrm{~cm}$. , mass $267.5 \mathrm{gm}$. Its moment of inertia, measured with a bifilar, was 3864 C.G.S. units, its mean area $794 \mathrm{~cm}^{2}$

There was also an added moment of inertia of from 0.005 to 0.023 , according to the size and position of the attached mirror. The alternating current in the coils was 0.5 a mpere (effective value). The suspension was chosen to give a time of swing of the order of 20 seconds, a thin galvanometer suspension for the two rings, and a copper wire for the solenoid. Damping took place under a steady current of 1 to 2 amperes, which increased the mean natural $\lambda$ by a quantity of the order 002 .

The following are the results of four experiments on each 
of the circuits. With the solenoid a steady current of 2 amperes was used throughout; the temperature rose from $15^{\circ}$ to $20^{\circ}$ during an experiment, and was allowed for.

Copper ring (1):

$$
\begin{aligned}
& \mathrm{R}=6 \cdot 68 \times 10^{5}, 6 \cdot 62 \times 10^{5}, 6 \cdot 64 \times 10^{5}, 6 \cdot 52 \times 10^{5}: \\
& \text { mean } 6 \cdot 61 \times 10^{5} \text { absolute E.M.U. } \\
& \mathrm{L}=85 \cdot 6,84 \cdot 0,84 \cdot 3,78 \cdot 9: \text { mean } 83 \cdot 2 \mathrm{~cm} . \\
& \mathrm{L} \text { calculated from the dimensions } 85 \cdot 3 \mathrm{~cm} \text {. (low }
\end{aligned}
$$

Aluminium ring (2):

frequency).

$R=3.00 \times 10^{5}, 3.03 \times 10^{5}, 3 \cdot 12 \times 10^{5}, 3 \cdot 18 \times 10^{5}:$

mean $3 \cdot 08 \times 10^{5}$.

$\mathrm{L}=50 \cdot 2,54 \cdot 2,54 \cdot 2,56 \cdot 5:$ mean $53 \cdot 8 \mathrm{~cm}$.

$\mathrm{L}$ calculated from the dimensions $54 \cdot 7$ (Weinstein's formula).

Solenoid (3). Resistances reduced to $15^{\circ} \mathrm{C}$. :

$\mathrm{R}=4 \cdot 45 \times 10^{8}, 4.32 \times 10^{8}, 4.50 \times 10^{8}, 4.58 \times 10^{8}:$

mean $4.46 \times 10^{8}$.

R measured on bridge $4.542 \times 10^{\circ}$.

$\mathrm{I}_{\mathbf{1}}=2 \cdot 65 \times 10^{5}, 2.88 \times 10^{5}, 2 \cdot 80 \times 10^{5}, 2 \cdot 81 \times 10^{5}:$

mean $2.78 \times 10^{5} \mathrm{~cm}$.

L from deflexion experiments, taking bridge value of $\mathrm{R}, 2.88 \times 10^{5} \mathrm{~cm}$.

L calculated from the dimensions, with spacing correction $* 2 \cdot 89 \times 10^{5} \mathrm{~cm}$.

L measured with a wavemeter and buzzer, $2.9 \pm \times 10^{5} \mathrm{~cm}$.

It appears that the method is uncertain to abuut 5 per cent., and in addition there is a correction for ware-form, which may amount to 3 per cent. We are also limited to fairly thick rings in the damping experiment.

\section{High-frequency experiments.}

Much better results are obtained with frequencies of the order used in wireless telegraphy. The results are independent, to a considerable degree, of the frequency and tha resistance of the circuit. Formula (2) is usually very close ; for a second approximation we subtract $\mathrm{R}^{2} / \mathrm{L}_{1}{ }^{2}$ from $\mathrm{L}$,

* For a convenient collection of formula and tables, see Nottage, 'Calculation and Measurement of Inductanee and Capacity' (Wireless Press). 
where $\mathrm{R}$ is calculated at the frequency used in the experiments. In designing the high frequency circuit we should have comparatively few turns in the deflecting coil, in order to reduce self-capacity, which causes inequality of current in the various parts. It is nevertheless easy to obtain sufficient deflexion, and it was found convenient to work with a Duddell's thermo-ammeter at a current of about 0.05 ampere. The circuit is shown in the figure. The deflecting coils DD

Fig. 1.
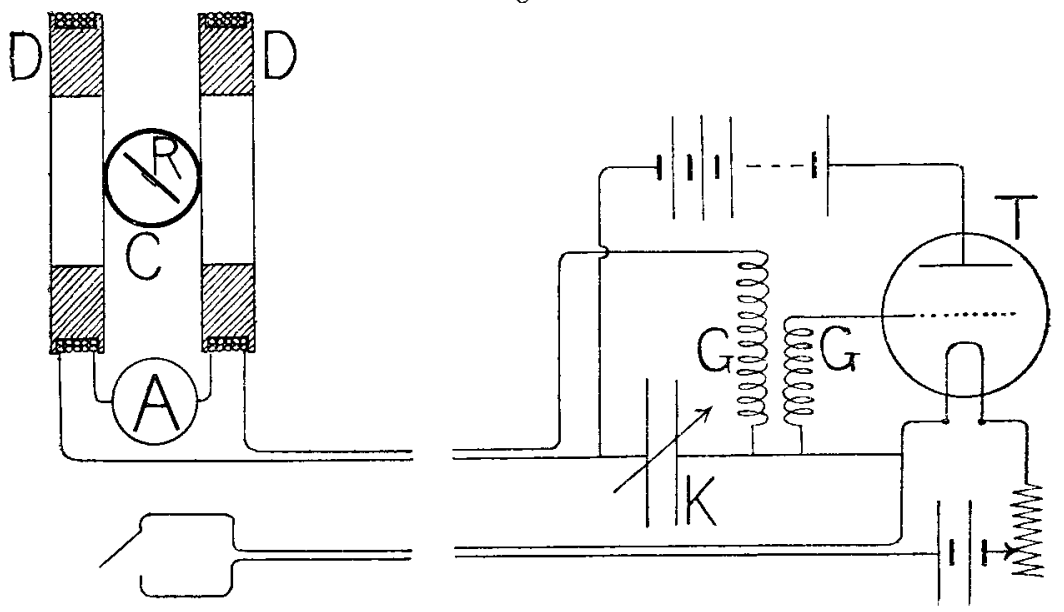

formed an approximate Helmholtz pair, each having 50 turns of cotton-covered S.W.(*. 20 wound on a hard wooden core of $13 \mathrm{~cm}$. diameter, the mean outside diameter being $13.84 \mathrm{~cm}$. and the separation between centres $7.12 \mathrm{~cm}$. A cardboard cylinder (! was pressed tightly between the coils, and was cut for the insertion of thin mica windows. The ring $\mathrm{R}$, with small mirror attached, was hung by a galranometer suspension from an ebonite rod, which passed through a plug fitting loosely into the cardboard cylinder. The thermo-ammeter $A$ was normally inserted between the coils. Experience showed that the disturbing effect of the generating coils $G G$ might be considerable, and they were consequently removed to a distance of 3 metres, with a counexion of twisted flexible wire. The condenser $\mathrm{K}$ was of $1 \mathrm{mmfl}$. maximum capacity, giving oscillations of wavelength 3250 metres. The triode $T$ was of the French type, with a 4 -volt heating battery and 200 rolts on the anode. Flexible leads were also brought from the heating circuit to a key near the scale, by which the oscillations of the ring $\mathbf{R}$ could be conveniently controlled. 
Preliminary standardizations were as follows:-The magnetic field at the centre of the ring for a current of 1 ampere was 6.46 gausses, by calculation. For checking, it was found most accurate to compensate the field with a second circuit of known dimensions, replacing $R$ by a small magnet with attached mirror. The ratio of the currents wis found by a bridge method while in position. Comparison was made with the large Helmholtz pair, and with a square frame accurately wound with a single laver of open turns. These gave 6.49 and 6.45 respectively. The value 6.47 is adopted.

In order to check the constancy of current in the coils the thermo-ammeter was placed (1) to the left, (2) brtween the coils, (3) to the right, under otherwise identical conditions. The mean of two observations of each current gave scale readings of $54 \cdot 65,54 \cdot 20,54 \cdot 45$, respectively. The mean, taking the middle twice, is $54 \cdot 37$. We therefore add $0 \cdot 17$, or 3 parts in 1000, to the readings of the middle current. This correction is near the limits of observational error, l,ut I have thouglit best to include it. The thermo-ammeter "as calibrated before and after each experiment with a Weston cell circuit, arranged to give a current of 0.0509 ampere.

\section{Experimental results.}

The solenoid (3) was too large to use : experiments were made on (1) and (2) and on the two following circuits:-

(4) A copper ring of mean radius $0.525 \mathrm{~cm}$. and diameter of wire $0.054 \mathrm{~cm}$. , mass $0.0695 \mathrm{gm}$. The calculated moment of inertia about a diameter was $(1.00977$, or with the very small attached mirror $0 \cdot 00978$, its mean area $0.860 \mathrm{~cm}^{2}$

(5) A solenoid of 61 turns of enamelled wire on a hollow ebonite eylinder. Mean diameter $2.03 \mathrm{~cm}$., length of winding $1.87 \mathrm{~cm}$. Mass of cylinder $5.802 \mathrm{gm}$, of wire $2.082 \mathrm{gm}$. Diameter of wire over enamel $0.030 \mathrm{~cm}$., under ename $0.025 \mathrm{~cm}$. The calculated moment of inertia of the cylinder was $9 \cdot 14$, of the wire $1 \cdot 70$. Mean area $3 \cdot 238 \mathrm{~cm}^{2}$

The deflexions, and the readings of the thermo-ammeter during an experiment, were extremely steady. The scale was set up at exactly 1 metre from the suspending fibre. The mirror was set on accurately parallel to a large mirror placed temporarily across the ring. The lamp was placed quadrantally, so that a reading in the midule of the scale 
corresponded to the position $\theta=\frac{1}{4} \pi$ of the ring. The following figures for ring (1) will show how the experiments were conducted :-

Zero $46 \cdot 60 \mathrm{~cm}$.

Final position $27 \cdot 02 \mathrm{~cm}$.

Thermo-ammeter $58 \cdot 2$.

Calibration 0509 ampere $=49 \cdot 2$ on scale.

Time of 10 swings $135 \cdot 2,134 \cdot 8,135^{\circ} 0 . \quad \mathrm{T}=13 \cdot 50$ secs. True $\mathrm{H}=1 \cdot 003 \times 6 \cdot 47 \times \frac{58 \cdot 2}{49 \cdot 2} \times 0509=0 \cdot 3907^{\cdot}$ gauss.

Angular deflexion of ring, reduced to are, $\frac{1}{2}(\cdot 1923)$.

$$
\mathrm{L}=\frac{(3907 \times 12 \cdot 95 \times 13 \cdot 50)^{2}}{39 \cdot 48 \times 7 \cdot 565 \times 1923}=81 \cdot 2 \mathrm{~cm} \text {. }
$$

The resistance of the ring at 3250 metres $\left(p=5.8 \times 10^{5}\right)$ is calculated to be $1.8 \times 10^{6}$ absolute E.M.U. The correction $\mathrm{R}^{2} / \mathrm{L} p^{2}$ is $0 \cdot 12$, giving $\mathrm{L}=81.1 \mathrm{~cm}$. from the experiments. Repetition also gave $81 \cdot 1$. The theoretical inductance ${ }^{*}$ at the same frequency is $81 \cdot 7 \mathrm{~cm}$.

The aluminium ring gave $L=52 \cdot 4 \mathrm{~cm}$. and $51.8 \mathrm{~cm}$. in two experiments. The theoretical inductance for a ring of circular cross-section and the same area is $51.0 \mathrm{~cm}$. at 3250 metres. The copper $\operatorname{ring}(4)$ gave $\mathrm{L}=22.56 \mathrm{~cm}$. and $22.68 \mathrm{~cm}$. in two experiments uncorrected for resistance. A quartz fibre was used. The resistance correction is rather high, $0.93 \mathrm{~cm}$. On the mean we have therefore $21.7 \mathrm{~cm}$. for the inductance at 3250 metres. Calculation gives $21.7 \mathrm{~cm}$. The small solenoid (5) gave $\mathrm{L}=51700 \mathrm{~cm}$. before correction. The low-frequency resistance was $1 \cdot 04$ ohms. A rough experiment to ascertain the resistance at 3250 metres gave values 1.0 and $1 \cdot 2$ ohms. Since $\mathrm{L} p$ is about $30 \mathrm{ohms}$, the resistance correction is hardly appreciable. The calculated inductance, with spacing correction, is $53,700 \mathrm{~cm}$. The correction for frequency is not known, but not likely to exceed $100 \mathrm{~cm}$. An experiment with a known capacity, wavemeter, and buzzer, gave $\mathrm{L}=52,000 \mathrm{~cm}$. Collecting these results, we have :-

Inductance at 3250 metres.

$\begin{array}{lcc}\text { Ring (1) } \ldots \ldots \ldots \ldots \ldots \ldots & 81 \cdot 1 & \begin{array}{c}\text { Obs. } \\ \text { Calc. }\end{array} \\ \text { Ring (2) } \ldots \ldots \ldots \ldots \ldots \ldots . & 52 \cdot 1 & 51 \cdot 0 \\ \text { Ring (4) } \ldots \ldots \ldots \ldots \ldots \ldots & 21 \cdot 7 & 21 \cdot 7 \\ \text { Solenoid (5) } \ldots \ldots \ldots \ldots \ldots & 51700 & 53700\end{array}$

* Neglecting the effect of curvature. For tables, see Jahnke-Emde, Funktionentafeln, p. 147. 
For much greater accuracy the moments of inertia wonld have to be checked by experiment.

The experiments with the small ring are interesting in showing how much further we can go. The deflexion, with an ordinary electrometer suspension, w as approximately $23 \mathrm{~cm}$. on the scale, for a current of 0.06 ampere. With geometrical proportionality the deflexion varies as the cube of the linear dimensions. 'Thus with a ten times weaker fibre and a current of 2 amperes, a circle of inductance 1 would give a deflexion of $1 \mathrm{~cm}$. It is clear, therefore, that the fimit would be reached by mechanical difficulties long before the deflexion became inappreciable. The resistance correction could be kept down by cooling in liquid hydrogen.

\section{Summary.}

The inductance of a number of small loops is measured by suspending them in an alternating magnetic field. The lowfrequency experiments are inaccurate : with high-frequency current inductances from $20 \mathrm{~cm}$. to $50,000 \mathrm{~cm}$. are measured with an average error of $1 \frac{1}{2}$ per cent.

These experiments were performed in the Electrical Laboratory, Oxford, by kind permission of Prof. T'ownsend. I am indelsted to Mr. C. A. Bowen, Exhibitioner of Corpus Christi College, for valuable help in taking the ohservations.

XXVII. The Disappearance of Gus in the Elertric Dischurue. -III. By The Research Staff of the General Electric Company, Ltd, London*. (Work conducted ly N. R. (ampbella.)

(Continued from vol, xl. p. 585 and vol. xli. p. 685.)

\section{Summaru.}

1-5. $7 \mathrm{TE}$ previous work has shown that, except in 1 hydrogen, the absorption of gas occurs only if there is a glow discharge. If absorption is determined by electrical conditions at all, it is to be expected that it is closely associated with ionization of the gas ahsorbed. - Some previous experiments might appear inconsistent with this hypothesis. This difficulty is now removed by showing that, in a discharge vessel with electrodes of which the area is small compared with that of the walls, those walls can act as a third electrode, receiving almost all the positive ions, the charge on which is neutralisel by electrons from the cathode. Moreover, in such a vessel, the free path of the

* Communicated by the Director. 